\title{
Thyroid function tests and its interpretation
}

\author{
${ }^{1}$ KC Shiva Raj
}

${ }^{I}$ Department of pathology, KIST medical college and hospital, Lalitpur, Nepal

\author{
Keywords: \\ Hypothyroidism; \\ Hyperthyroidism; \\ Thyroiditis; \\ Thyroxine; \\ Thyroid stimulating \\ hormone; \\ HAMA.
}

\begin{abstract}
Abstract: Thyroid diseases are among the most prevalent of medical conditions. In the patients with obvious features of hypothyroidism or hyperthyroidism thyroid function tests only confirm the diagnosis. Though TSH is widely used as a screening test in suspicion with thyroid disorder, many times TSH alone may be misleading. In this situation TSH along with T4 and T3 should be performed which will resolve the problem. However, thyroid function tests may not concord with each other. Discordant results between TSH, T4 and T3 may be because of various conditions like subclinical hypo- or hyperthyroidism, non-thyroidal illness, drugs etc. Beside that antibody interference and special condition like pregnancy may alter the thyroid hormone concentration.
\end{abstract}

\section{INTRODUCTION}

Thyroid diseases are among the most prevalent of medical conditions. The patient may present with obvious features of hypothyroidism or hyperthyroidism. In these conditions thyroid hormone $(\mathrm{TH})$ concentration only confirm the diagnosis. However, in many patients the signs or symptoms can be nonspecific, vague or mild, especially in females. In these conditions, clinicians have to rely on the laboratory for assistance in the diagnosis of thyroid disorders.

In the 1950s, only serum total thyroxine (TT4) was available investigation, in which protein bound iodine technique was used. Since 1970, technological advances in radioimmunoassay (RIA) and immunometric assay (IMA) methodologies have significantly improved the specificity and sensitivity of the thyroid testing methods allowing an accurate diagnosis of thyroid status to be made in the majority of cases. ${ }^{1}$ However, sensitivity, specificity and standardization issues still result in substantial between

\section{Correspondence:}

Dr. Shiva Raj K.C. MBBS, MD

Department of Pathology

KIST medical college, Imadole, Lalitpur, Nepal

Email:shiva_kc_123@yahoo.com method variability for many of these tests, and analytical interference is still a common problem. This article aims to review the indications for thyroid function tests and their interpretation.

\section{THYROID STIMULATING HORMONE}

The first-line of blood test performed; for thyroid diseases; depends on the local availability of tests and laboratory protocols. Many clinicians prefer thyroid stimulating hormone (TSH) as the initial screening test for suspected patient with thyroid disease as it is the key hormone for diagnosing hyperthyroidism and hypothyroidism. ${ }^{2}$ The reason behind TSH being the screening tests is because, it is central to the negative feedback mechanism and tiny variation in thyroid function causes dramatic changes in TSH secretion. With the use of most advanced third generation chemiluminescent TSH assay it is now possible to detect both significant raised and decreased TSH levels and are capable to detect as low as $<0.1 \mathrm{mU} / \mathrm{L}$ of TSH.

Normal range is approximately $0.5-4.5 \mathrm{mU} / \mathrm{L} .{ }^{3}$ The American Association of Clinical Endocrinologists (AACE) has revised these guidelines as of early 2003, narrowing 
the range 0.3-3.0 mU/L. Over the past few years the TSH reference interval has become controversial. The lower TSH reference limit has been shown to be approximately $0.3 \mathrm{mIU} / \mathrm{l}$ irrespective of the population or the method used. In contrast, the setting of the TSH upper reference limit has become contentious with estimates ranging from $2.1 \mathrm{mIU} / 1$ to $7.5 \mathrm{mIU} / 1 .{ }^{4}$ Serum TSH normally exhibits a diurnal variation with a peak shortly after midnight and a nadir in the late afternoon. At the peak of this variation the TSH can be double the value at the nadir. ${ }^{4}$ TSH values can be expected to vary by as much as $20 \%$ between measurements without any change occurring in thyroid status. ${ }^{4}$

\section{TSH may be decreased in the following conditions:}

- Primary hyperthyroidism

- Pituitary/hypothalamic disease

- Prolonged thyrotroph cell suppression after recent hyperthyroidism in euthyroid or hypothyroid patient

- Old age

- Drugs, e.g., glucocorticoids, dopamine

- Non thyroidal illnesses

- Combination of pulsatile TSH secretion and analytical precision limits

TSH may be elevated in the following conditions:

- Primary hypothyroidism

- Pituitary adenoma (TSH producing)

- Pituitary resistance to thyroidhormone (TSH, unreliable)

- Generalized thyroid hormone resistance

- Thyrotoxicosis from overly rapid correction of severe hypothyroidism with use of parenteral thyroxine

- Old age

- Drugs, e.g., amiodarone

- Recovery phase after severe systemic illness

- Combination of pulsatile TSH secretion and analytical precision limits

- Antibody in patient serum against antibody in TSH assay, causing analytical artifact

However, it should be kept in mind that TSH alone; for the diagnosis of thyroid disease; can when the pituitary-thyroid axis is normal. If any patient is suffering from non-thyroidal illness (NTI), pituitary disease and drugs (glucocorticoids, tyrosine kinase inhibitor, octreotide etc.) can affect this axis and cause disagreements between TSH levels, and T4, T3 along with clinical features of the individuals. 4If TSH

\author{
Table 1: Conditions in which measurement of TSH alone \\ may be misleading \\ Central hyperthyroidism (Secondary to TSH producing pituitary \\ adenoma) \\ Central hypothyroidism (Secondary; rare) \\ Patient undergoing treatment for thyroid illness \\ Non-thyroidal illness \\ TSH assay interference (HAMA antibody) \\ Resistant to thyroid hormone \\ AML in Down syndrome \\ Blastic plasmacytoid dendritic cell neoplasm
}

alone is done for identifying the status of thyroid function it may be misleading in certain condition. (Table. 1) The serum half-life of TSH is approximately 1 hour whereas half-life of free thyroxine (fT4) is approximately 1 week which results in discordant TSH/fT4 values for certain duration

Similarly, in patients with pituitary hypothyroidism in which TSH remains within normal range or in patients undergoing long term treatment for hyperthyroidism and now in hypothyroid state will still be having suppressed TSH levels. ${ }^{5,6}$ In TSH secreting pituitary tumour or in thyroid hormone resistant cases the TSH level will usually be normal. When we are suspecting TSH secreting pituitary tumour serum sex hormone binding globulin and circulating free $\alpha$ subunit should be tested which should be elevated. Family history, $\beta$ thyroid hormone receptor sequencing may help to diagnose syndrome of thyroid hormone resistance. "Inappropriate" TSH is coined when inappropriately raised TSH is observed along with raised fT3 and fT4. This condition may attribute to laboratory errors which should be ruled out first. Other explanation should be searched for apparent elevation of fT4 which may be due to presence of binding protein abnormalities or assay dependent antibody interference while measuring TSH, fT4 or free triiodothyronine (fT3). ${ }^{1}$ Thus when the results of the TSH test are abnormal, then subsequent tests of fT4 and fT3 should be performed. When all three thyroid tests are normal then thyroid disease can be confidently excluded except in patient with already in treatment. In various condition different patterns of association is noted between TSH, fT4 and fT3.

Table 2: Typical thyroid function test results in hypothyroidism

\begin{tabular}{llll}
\hline \multirow{2}{*}{ Causes } & & Thyroid function tests & \\
\cline { 2 - 4 } & TSH & T4 & T3 \\
Ioidine deficiency disorder & Increase & Decrease & Decrease \\
Hasimoto's thyroiditis & Increase & Normal/Decrease & Normal/Decrease \\
Pituitary abnormality & Decrease & Decrease & Decrease \\
Non-thyroidal illness & Variable & Normal/Decrease & Decrease
\end{tabular}


Table 3: Typical thyroid function test results in hypothyroidism

\begin{tabular}{llll}
\hline \multirow{2}{*}{ Causes } & & Thyroid function tests & \\
\cline { 2 - 4 } & TSH & T4 & T3 \\
Grave's disease & Decrease & Increase & Increase \\
Hasimoto's thyroiditis (early stage) & Decrease & Increase & Increase \\
Increase & Decrease & Increase & Increase
\end{tabular}

\section{THYROXINE}

The concentrations of $\mathrm{T} 4$ below or above the normal range in absence of thyroid dysfunction, is as a result of an abnormal level of serum thyroid binding globulin (TBG). Such abnormally high values are observed in many physiological conditions in women with hyperestrogenic state of pregnancy. ${ }^{3}$ Hyperthyroidism and hypothyroidism can be associated with abnormal menstrual cycles. ${ }^{3}$ Small seasonal variations and changes related to high altitude, cold and heat are also seen. The variation is also related to postural changes in serum proteins concentration and true circadian variation. There is increased binding to serum proteins in cases of familial dysalbuminemic hyperthyroxinemia(FDH) which shows increased TBG. Subclinical primary hypothyroidism is more common in persons with chronic kidney disease (CKD). ${ }^{7}$

A minute amount of thyroid hormone circulates in the blood in a free form, not bound to serum proteins. It is in reversible equilibrium with the bound hormone and represents the diffusible fraction of the hormone capable of traversing cellular membranes to exert its effects on body tissues. ${ }^{8}$ The normal values for freeT4 in adults range from 1.0 to $3.0 \mathrm{ng} / \mathrm{dL}$ (13 to $39 \mathrm{pmol} / \mathrm{L}$ ). ${ }^{3}$ Although changes in serum hormone-binding proteins affect both the total hormone concentration and the corresponding fraction circulating free in the euthyroid person, the absolute concentration of fT4 remains constant and correlates with the tissue hormone level and its biologic effect. ${ }^{8}$ Serum fT4 may be suppressed in the patients with thyroidal illness and transiently rise in acute thyroidal illness, when thyroid-binding protein frequently falls. ${ }^{9} \mathrm{~T} 4$ test should be performed to optimizing thyroxine therapy in newly diagnosed patientswith hypothyroidism and hyperthyroidism. T4 is required to diagnose for secondary hypothyroidism and also in case of end organ thyroid hormone resistance.

T4 may be elevated in the following conditions:

- Hyperthyroidism

- Graves' disease,

- Plummer's disease (toxic thyroid adenoma),

- early phase of acute thyroiditis,

- Struma ovarii

- Luft's syndrome (Hypermetabolic Mitochondrial Miopathy- in some cases).

\section{T4 may be decreased in the following conditions:}

- Primary hypothyroidism (thyroid failure)
- Secondary hypothyroidism (pituitary failure)

- Tertiary hypothyroidism (hypothalamic failure)

Treatment with oral estrogen results in a marked increase in thyroxine-binding globulin. The total serum capacity forthyroid hormone is therefore increased. In normal subjects, this results in an increase in total $\mathrm{T} 4$ but only in a transientdrop in free T4. However, in hypothyroid patients receiving thyroxine, a persistent elevation of TSH is observed and doseadjustments are necessary. This effect is not observed withtransdermal estrogen therapy, as the absence of liver passageof the drug results in a much weaker effect on thyroxine binding globulin synthesis. ${ }^{10}$

\section{TRIIODOTHYRONINE}

Serum Total Triiodothyronine reflects the functional state of peripheral tissue rather than secretory performance of the thyroid gland. Sex difference is small, but age difference is more dramatic. The fall in TT3, might reflect prevalence of non-thyroidal illness rather than an effect of age alone. ${ }^{11}$ Positive co-relation between serum TT3 level and body weight has been observed. ${ }^{12}$ The principle uses for obtaining the serum T3 are to determine the severity of hyperthyroidism, and to confirm the diagnosis of suspected thyrotoxicosis in which serum T4 levels are normal or equivocal. In addition it may be required to carry out the test in cases of functioning thyroid adenomas, where T3 toxicosis may be present and such patients may have normal or borderline elevated serum $\mathrm{T} 4$ levels along with suppressed serum TSH levels. ${ }^{13}$ Serum T3 is misleadingly elevated in women who are pregnant or who take oral estrogen, due to the high serum levels of TBG in these conditions. ${ }^{9}$ Free triiodothyronine (FT3) measures the very tiny amount of T3 that circulates unbound. It is useful in looking for hyperthyroidism or thyroxine overplacement in women who are pregnant or taking any effective drugs that vary the TBG like estrogen. ${ }^{9}$ More consistently, patients with a variety of non-thyroidal illnesses have low FT3 level. ${ }^{3}$ This decrease is characteristic of all conditions associated with depressed serum TT3 concentrations due to a diminished conversion of T4 to T3 in peripheral tissues. ${ }^{14}$ The FT3 concentration is usually normal or even high in hypothyroid persons living in areas of severe endemic iodine deficiency and their FT4 levels are, however, normal or low. ${ }^{15}$

\section{HYPOTHYROIDISM}

In Primary hypothyroidism TSH will be elevated and fT4 
and fT3 are decreased. Primary hypothyroidism is caused by various conditions namely Graves' disease, multinodular goitre, or toxic nodule in which TSH is usually very low (Table 2). Further clinical features help to separate these three conditions. Similarly, features of hypothyroidism may be seen in patient getting treatment for hyperthyroidism, patient who had undergone total thyroidectomy along with patient who had history of radiation. Rare conditions like congenital condition when thyroid tissue is absent, thyroid disgenesis, iodine transport defect, intake of goitrogens (broccoli, cabbage) may also lead to hypothyroidism. Other condition includes systemic amyloidosis, Riedel's thyroiditis, thyroglobulin synthesis defect in which there will be low thyroglobulin concentration etc. ${ }^{16}$ Secondary hypothyroidism may occur due to various drugs like amiodarone, lithium etc. ${ }^{17}$ Even excess intake of iodine may lead to hypothyroidism. Disease like pituitary tumor or Sheehan syndrome or any surgery of pituitary may also lead to hypothyroidism.

However, while interpreting thyroid function tests, one should not forget subclinical hypothyroidism in which TSH is raised while fT4 and fT3 are within normal range. In some condition only fT4 may be decreased whereas TSH is raised and fT3 may be normal or even supranormal. ${ }^{18}$

\section{HYPERTHYROIDISM}

Hyperthyroidism is a pathological syndrome in which tissue is exposed to excessive amounts of circulating thyroid hormone. Typical findings of thyroid function test are shown in Table 3. In Primary hyperthyroidism TSH will be decreased and fT 4 and fT 3 are increased. The most common cause of this syndrome is Graves' disease, followed by toxic multinodular goitre, and solitary hyperfunctioning nodules. Autoimmune postpartum and subacute thyroiditis (Hasimoto's thyroiditis, De Quervain's thyroiditis, lymphocytic thyroiditis) is relatively common diseases with low radioiodine uptake. Other less common causes include thyroxine ingestion, Struma ovarii. Secondary hyperthyroidism is seen in patient with pituitary tumors that secrete thyrotropin, and drug-induced thyroid dysfunction (amiodarone), are also important causes. Amiodarone may cause hyperthyroidism up to $10 \%$ of cases. ${ }^{19}$ Rarely individuals may have resistance to thyroid hormone syndrome in whom there is marked elevation in both FT4 and FT3 concentrations in the absence of hypermetabolism are typical of patients with resistance to thyroid hormone. ${ }^{20}$ In cases of Anti-TPO antibodies are on occasion detectable and can be useful, in the absence of histology, to differentiate postviral and silent thyroiditis. The causes of thyrotoxicosis with a low radioiodine uptake include thyroxine ingestion (therapeutic or factitious), ectopic thyroid tissue (including Struma ovarii), amiodarone therapy, and excess iodine ingestion (typically seen in multinodular goitre-JodBasedow effect). An increase in thyroid tissue favors the last condition.

Some of the patients may present with subclinical hyperthyroidism in whom TSH is low and normal fT3 and fT4 which is also seen in patient with thyroxine treatment for hypothyroidism

\section{RESISTANCE TO THYROID HORMONE}

Resistance to thyroid hormone (RTH) is a syndrome in which the responsiveness of end organs to $\mathrm{TH}$ is reduced. RTH syndrome is due to a loss-of-function mutation in the humanTHRB gene (TR $\beta$ RTH). TR $\beta$ RTH has an estimated incidence of 1 in 40-50,000 live births. ${ }^{21}$ Since the THresponsive end-organs include pituitary $\mathrm{TSH}$, almost all patients with RTH present with elevated TSH despite elevated fT4 and fT3 levels. This abnormal finding in the thyroid function test is termed "syndrome of inappropriate secretion of TSH" (SITSH) or "central hyperthyroidism". ${ }^{22}$

\section{INTERPRETATION OF THYROID FUNCTION TESTS IN SPECIAL PATIENT POPULATION}

\section{Nonthyroidal illness}

A condition characterized by abnormal thyroid function tests encountered in patients with acute or chronic systemic illnesses is described as non-thyroidal illness (NTI). In this condition there is no intrinsic abnormality of hypothalamuspituitary-thyroid axis and occurs due to secondary adaptive changes. ${ }^{23}$ After the onset of NTI as early as 24 hours changes in T3 and TSH is noted in patients with chronic liver disease, chronic kidney disease, after surgery, myocardial infarction, malignancy, sepsis, burns, malignancy and even individual with poor nutrition. ${ }^{24,25}$ In NTI, TFT pattern is abnormal which may further evolve or change as the underlying primary disease does. fT4 and fT 3 become low or low-normal while TSH remains normal or even low. ${ }^{26,27}$ However, it is not uncommon to find elevated fT4 level. Even more, same sample may yield totally variable fT4 and fT3 level. ${ }^{27}$ If total thyroid hormone concentrations are measured, even in mild NTI, there is marked reduction in T4 and T3 level. This is due to reduced thyroid binding protein concentration which leads to decreased in serum thyroid hormone binding capacity in ill patient. The magnitude of T4 decrease has been reported to correlate with a less favorable outcome In case with acute, major psychiatric illness, T4 is elevated with normal TSH value which in some patients come to normal level in a short interval of time ( $<2$ weeks). In others, TSH may be elevated or suppressed with normal T4 or T3. ${ }^{28}$ During recovery from intercurrent illness, TH and TSH concentrations return to normal. However, in some patients TSH may remain elevated for a short period of time which precedes the elevation in T4 and T3 level, suggesting that it is required for the restoration of euthyroidism. ${ }^{29}$ It is important to be aware of this transient phenomenon in order to avoid inappropriate diagnosis and treatment. Thus TFT should be avoided in ill patients until or unless it is required 
for the management of the patients.

\section{Pregnancy}

Under normal circumstances, almost two thirds of circulating T4 is bound to thyroxine binding globulin (TBG). The concentration of the major plasma binding protein for T4and T3, thyroxine-binding globulin (TBG), doubles during pregnancy. ${ }^{30,31}$ Estrogen induced increased hepatic synthesis coupled with decrease rate of degradation of TBG levels give rise in TBG level. Accordingly, serum total T4 and $\mathrm{T} 3$ concentrations increase to approximately $150 \%$ of non-pregnant values - this occurs during the first half of pregnancy and is maintained thereafter until parturition. ${ }^{32}$ This leads to transient fall in fT4 and fT3 concentration. During early period of pregnancy hCG level is significantly increased which has intrinsic but weak thyrotropic activity. So increase in HCG level is accompanied by a reciprocal decrease in the mean serum TSH concentration. ${ }^{30,33}$ In its most extreme form (hyperemesis gravidarum), affected women may become overtly thyrotoxic with a fully suppressed TSH. In this setting, it is important to distinguish gestational hyperthyroidism from other common causes of thyrotoxicosis (e.g. Graves' disease) as the management of these conditions differs significantly. ${ }^{34}$ Also, patients with gestational trophoblastic diseases sometimes develop thyrotoxicosis, and abundant evidence incriminates hCG as the thyrotropic factor causing thyroidal hypersécrétion in these women. ${ }^{35}$ As hCG levels decline, fT4 decreases. ${ }^{36}$ fT4 concentrations are often lower than those observed in the non-pregnant state, which may lead to concern regarding the possibility of central thyroid dysfunction if values are compared with non-pregnant reference ranges. Changes in FT3 broadly parallel those of FT4. TSH levels are restored as hCG levels fall in the second and third trimester.Other factors like increased glomerular filtration rate (increased iodine clearance), increased circulating plasma volume, enhanced DIO3 activity may alter the thyroid status in pregnancy. ${ }^{37,38}$

\section{Drugs}

A variety of drugs can alter the function of thyroid which results in alteration in thyroid hormones concentration. Some drugs like alemtuzumab which is an immune modulator and is used to suppress immune system in various autoimmune diseases which induces features similar to that of Graves' disease. Graves' disease has also been reported in several casesduring high activity antiretroviral therapy (HAART) in patients with human immunodeficiency virus infection. ${ }^{39}$ The possibility may be HAART may precipitate Graves' disease in predisposed subjects. Lithium is highly effective in the long-term management ofbipolar disorder. Overall,the effects of lithium on thyroid physiology are reminiscent the Wolff-Chaikoff effect, obtained through the administrationof high-dose iodine. The causefor the goiter likely lies in chronic subtle thyroid dysfunction, but direct proliferative effects of lithium on thyroid functionhave also been proposed. ${ }^{40}$ Some drugs alter the concentration of TBG in serum. Some drugs like estrogen, tamoxifen, fluoroucil, methadone cause increase in serum TBG which leads to increase in mainly total T4 and T3. However, increased serum TBG leads to transient alteration in fT4 and fT3 value. Other drugs like androgens, glucocorticoid, nicotinic acid inhibit the synthesis of TBG in liver thus alter the serum total and free thyroid hormones. ${ }^{32}$ Drugs like furosemide (especially $>80 \mathrm{mg} /$ day)aspirin, nonsteroidal anti-inflammatory agents, phenytoin, heparin (including low molecular weight), albumin and transthyretin are capable of displacing T4 and T3 from TH binding sites on TBG which alter hormone delivery to the site of its use, clearance and ultimately distorts the T4 and T3 concentration in serum. ${ }^{32}$

\section{Heterophilic antibodies}

Interfering antibodies are intrinsic antibodies that can cause unpredictable results on thyroid testing. They can be heterophile (nonspecific) antibodies, human anti-animal antibodies or autoantibodies to TSH, T4 or T3.Heterophilic antibodies (particularly HAMA) may affect immunometric assay methods more than competitive immunoassays. It forms a bridge between the signals andcapture antibodies which gives a false signal resulting in a high artifactual value. Moreover, the result may not beabnormal; it may be inappropriately normal. A potential forinfluencing results of neonatal screening also exists becauseantibodies are able to cross the placenta.HAMA (human anti-mouse antibodies) are relatively weak, polyreactive, multispecific antibodies that are frequently IgM. The presence of HAMA can alter the total as well as free T3, T4 and TSH results. Use of Fab fragments and heterospecies assay configurations can be employed as approaches to reduce this kind of interference. Specific human anti-animal antibodies (HAAA) are produced in response to well-defined specific antigens after exposure to therapeutic agents containing animal antigens or by coincidental immunization through workplace contact. Though assays for HAMA have been developed, there are large inter-method differences and therefore the reliability of these tests is questioned. ${ }^{1}$ Such interference in the TSH can be seen in cases of Graves' Disease and in patients with positive rheumatoid factor (RhF).Interfering antibodies may also bind the analyte (TSH) rather than the assay antibodies. ${ }^{43}$

\section{BIOLOGICAL VARIATION IN THYROID FUNCTION TESTS}

A circadian variation in serum TSH in healthy subjects is well documented. During the daytime serum TSH levels are low whereas, it rises by more than $100 \%$ just after midnight. No increment of serum T3 or T4 seems to follow the nocturnal surge in TSH. ${ }^{44}$ These fluctuations contribute to the width of the reference ranges. The circadian rhythm of TSH is influenced by environmental factors. Sleep decreases TSH pulse amplitude but not pulse frequency, as did fasting. Nocturnal physical activity may phase-delay 
the rhythms. ${ }^{45}$ Seasonal variation in T4 and TSH has also been documented. Serum T3 was higher during winter whileseasonal changes in T4 and TSH were less consistent. Seasonal variation has been suggested to be caused by ambient temperature and radiance and an increase in T3 with cold has been demonstrated. ${ }^{46}$

\section{CONCLUSION}

Although most thyroid function test patterns are easy to interpret, and usually concord with clinical assessment of thyroid status, a small subset of patients exhibit results that are either discordant with the clinical picture or not compatible with each other. In such cases, individual patient's analysis of clinical details including history along with structured approach to further assessment is essential to achieve correct diagnosis and proper treatment. Only then should further investigation for rare acquired and genetic causes of anomalous/discordant TFTs be considered.

\section{REFERENCES}

1. Joshi SR. Laboratory evaluation of thyroid function. JAPI 2011;59:14-20.

2. Wartofsky L, Dickey RA. Controversy in clinical endocrinology: the Evidence for a narrower thyrotropin reference range is compelling. J Clin Endocrin Metab 2005;90:5483-8. CrossRef

3. Roy EW, Sharon YW, Samuel R. Diagnostic Tests of the Thyroid, In: De Groot LJ, Leslie J, Jameson JL et al, eds. Endocrinology, volume 2, 5th edition. USA: Elsevier Saunders, 2006, pp1899-1913.

4. Haarburge D. Thyroid disease: thyroid function tests and interpretation CMEJ 2012:30. Available at URL http://www.cmej. org.za/index.php/cmej/article/view/2515/2432

5. Bakiri F. TSH assay in central hypothyroidism. Ann endocrinol1999;60:422-6.

6. Spencer CA. Dynamics of thyroid hormone suppression of serum thyrotropin: an invited commentary. Eur j endocrinol 1996;135:28586. CrossRef

7. Chonchol M, Lippi G, Salvagno G, Zoppini G, Muggeo M, Targher G. Prevalence of subclinical hypothyroidism in patients with chronic kidney disease. Clin J Am SocNephrol 2008;3:1296-300. CrossRef

8. Ekins R. Measurement of free hormones in blood. Endocrine Rev 1990;1:5-6. -8

9. Fitzgerald PA. Endocrinology, Disease of Thyroid gland. In: Maxin AP, Stephen JMP, Lawrence M et al, eds. Current Medical diagnosis and treatment, 49th edition. USA: McGraw Hill publication; 2007, pp 1138-1142.

10. Barbesino G. Drugs Affecting Thyroid Function. THYROID 2010;20:1635- . CrossRef

11. Koutras DA. Disturbances of menstruation in thyroid disease. Ann NY AcadSci 1997;816:280-284. CrossRef

12. Welle S, O' Connell M, Danforth E Jr, Campbell R. Decreased free fraction of serum thyroid hormones during the carbohydrate overfeeding. Metabolism1984;33:837-9. CrossRef

13. Surks MI, Chopra IJ, Mariash CN, Nicoloff JT, Solomon DH.American Thyroid Association Guidelines for use of laboratory tests in thyroid disorders. JAMA 1990;263:1529-32. CrossRef

14. Szkudlinski MW, Kazlauskaite R, Weintraub BD. Thyroidstimulation Hormone and Regulation of thyroid Axis, In: DeGroot LJ, Leslie J, Jameson JL et al, 5eds. Endocrinology, volume 2. USA: Elsevier Saunders, 2006. pp1803-60.
15. Delange F, Camus M, Ermans AM. Circulating thyroid hormones in endemic goiter. J Clin Endocrinol Metab 1972;34:891-5. CrossRef

16. Dayan CM. Interpretation of thyroid function tests. Lancet 2001; 357: 619-24. CrossRef

17. Ahmed S, Van Gelder IC, Wiesfeld AC, Van Veldhuisen DJ, Links TP. Determinants and outcome of amiodarone-associated thyroid dysfunction. Clin Endocrinol (Oxf) 2011;75:388-94. CrossRef

18. Chopra IJ, Hershman JM, Hornabrook RW. Serum thyroid hormone and thyrotropin levels in subjects from endemic goiter regions of New Guinea. J Clin Endocrinol Metab 1975;40:326-33. CrossRef

19. Harjai KJ, Licata AA. Effects of amiodarone on thyroid function. Ann Intern Med 1997;126:63-73. CrossRef

20. Shivaraj G, Desai PB, Sonal V, Shruthi K, Vinayak H, Avinash M. Thyroid function tests: a review. European Review for Medical and Pharmacological Sciences 2009; 13: 341-9. PMid:19961039

21. Snell M., Visser T., Beck-Peccoz P. Resistance to thyroid hormone. In: Jameson J.L., De Groot L.J., editors. Endocrinology. 6th ed. Saunders Elsevier; Philadelphia, PA: 2010.pp1745-59.

22. Murata Y. Syndromes of resistance to thyroid hormone and inappropriate secretion of TSH(SITSH).Nihon Rinsho. 2012;70:19517. PMid:23214067

23. Farwell A.P. Thyroid hormone therapy is not indicated in the majority of patients with the sick euthyroid syndrome. Endocrine Practice. 2008;14:1180-7. CrossRef

24. Kaptein EM. In: Thyroid hormone metabolism. Hennemann G., editor. Marcel Dekker; New York: 1986. pp. 297-334.

25. Docter R., Krenning E.P., de Jong M. The sick euthyroid syndrome: changes in thyroid hormone serum parameters and hormone metabolism. Clinical Endocrinology. 1993;39:499-518. CrossRef

26. Beckett G.J., Wilkinson E., Rae P.W. The clinical utility of a nonisotopic two-step assay (DELFIA) and an analogue radioimmunoassay (SimulTRAC) for free thyroxine compared. Annals of Clinical Biochemistry.1991;28:335-44. CrossRef

27. Beckett G.J. Thyroid function and thyroid function tests in nonthyroidal illness. CPD Bulletin: Clinical Biochemistry. 2006;7:10716.

28. Arem R, Cusi K. Thyroid function testing in psychiatric illness: usefulness and limitations. Trends in Endocrinology and Metabolism. 1997;8:282-7. CrossRef

29. Hamblin P.S., Dyer S.A., Mohr V.S. Relationship between thyrotropin and thyroxine changes during recovery from severe hypothyroxinemia of critical illness. Journal of Clinical Endocrinology and Metabolism. 1986;62:717-22. CrossRef

30. Glinoer D. De Nayer P. Regulation of maternal thyroid during pregnancy. J Clin Endocrinol Metab 1990;71:276-87. CrossRef

31. Refetoff $S 1989$ Inherited thyroxine-binding globulin abnormalities in man. Endocrine Rev 10:275-293. CrossRef

32. Koulouri O, Moran C, Halsall D, Chatterjee K,Gurnell M. Pitfalls in the measurement and interpretation of thyroid function testsBest Pract Res Clin Endocrinol Metab 2013;27:745-62. CrossRef

33. Harada A. Hershman JM, Reed AW.et al 1979 Comparison of thyroid stimulators and thyroid hormone concentrations in sera of pregnant women. J Clin Endocrinol Metab 48:793-802. CrossRef

34. Lazarus J.H. Thyroid function in pregnancy. British Medical Bulletin. 2011;97:137-48. CrossRef

35. Cave WT, Dunn JT. Choriocarcinoma with hyperthyroidism: Probable identity of the thyrotropin with human chorionic gonadtropin. Ann Intern Med 1976;85:60-63. CrossRef

36. Anckaert E., Poppe K., Van Uytfanghe K. FT4 immunoassays may display a pattern during pregnancy similar to the equilibrium dialysis ID-LC/tandem MS candidate reference measurement procedure in spite of susceptibility towards binding protein alterations. Clinica Chimica Acta.2010;411:1348-1353. CrossRef 
37. Brent G.A. Maternal thyroid function: interpretation of thyroid function tests in pregnancy. Clinical Obstetrics and Gynecology 1997;40:3-15.CrossRef

38. Levy RP, Newman DM. Rejali LS, Barford DAG. The myth of goiter in pregnancy. Am J Obstet Gynecol 1980;137:701-3. PMid:7395933

39. Jubault V, Penfornis A, Schillo F et al. Sequential occurrence of thyroid autoantibodies and Graves' disease after immune restoration in severely immunocompromised human immunodeficiency virus1-infected patients. J Clin Endocrinol Metab 2000;85:4254-7. CrossRef

40. Rao AS, Kremenevskaja N, Resch J, Brabant G 2005 Lithium stimulates proliferation in cultured thyrocytes by activating Wnt/ beta-catenin signalling. Eur J Endocrinol 153:929-38. CrossRef
41. Gurnell M, Halsall DJ, Chatterjee VK. What should be done when thyroid function tests do not makesense? Clinical Endocrinology 2011; 74:673-8. CrossRef

42. FisherDA.Physiological variations in thyroid hormones: Physiological and pathophysiological considerations. ClinChem1996;42:135-139. PMid:8565215

43. Buxton OM, Frank SA, L'Hermite-Balériaux M, Leproult R, Turek FW, von Cauter E 1997 Roles of intensity and duration of nocturnal exercise in causing phase delays of human circadian rhythms. Am J Physiol 1997;273:E536-E42. PMid:9316443

44. Leppaluoto J, Sikkila K, Hassi J. Seasonal variation of serum TSH and thyroid hormones in males living in subarctic environmental conditions. Int $\mathrm{J}$ Circumpolar Health 1998;57:383-385. PMid:10093311 